\title{
Kindness towards Others in Great Expectations
}

\author{
Saed Jamil Shahwan \\ Department of English, Faculty of Arts \\ Hail University, Saudi Arabia
}

\begin{abstract}
The novel, Great Expectation (1861) revolves around the universal theme of love and conflict, which influences the protagonist, Pip. Many critics have commented on the plot and background of the novel. The main aim of this study is to reveal various instances projecting kindness and sympathy in between the social conflict and social tension at the background of the novel "Great Expectation. The study will focus on the concept of kindness towards others which has been incorporated throughout the story of the novel between the narrator and the characters. Charles Dickens (1812-1870) has shed light upon the theme of social mobility, manners, social injustice and prospect towards tangible reality. This study answers the question whether Dickens could be able to reflect the concept of kindness in the novel or not? Moreover, it will search whether the concept of kindness has been explored well in the story of the novel that it contains probable educational contents of kindness for research. To prove that, the article will explore various aspects of kindness, which has been observed during the course of the novel. The study would be based on qualitative research method from secondary resources. The aspect of kindness would be analyzed and highlighted through multiple scenes from the novel. The study would be concluded on the point where Dickens stresses on the dialect for up gradation of social status in Pip in order to establish himself as a desired partner of Estella despite having a social difference of class during the Victorian period.

Keywords: Charles Dickens, dialect, expectations, kindness, mobility, social injustice, social tension
\end{abstract}

Cites as: Shahwan, S. J. (2019). Kindness towards Others in Great Expectations. Arab World English Journal for Translation \& Literary Studies, 3 (2) 49-55.

DOI: http://dx.doi.org/10.24093/awejtls/vol3no2.5 